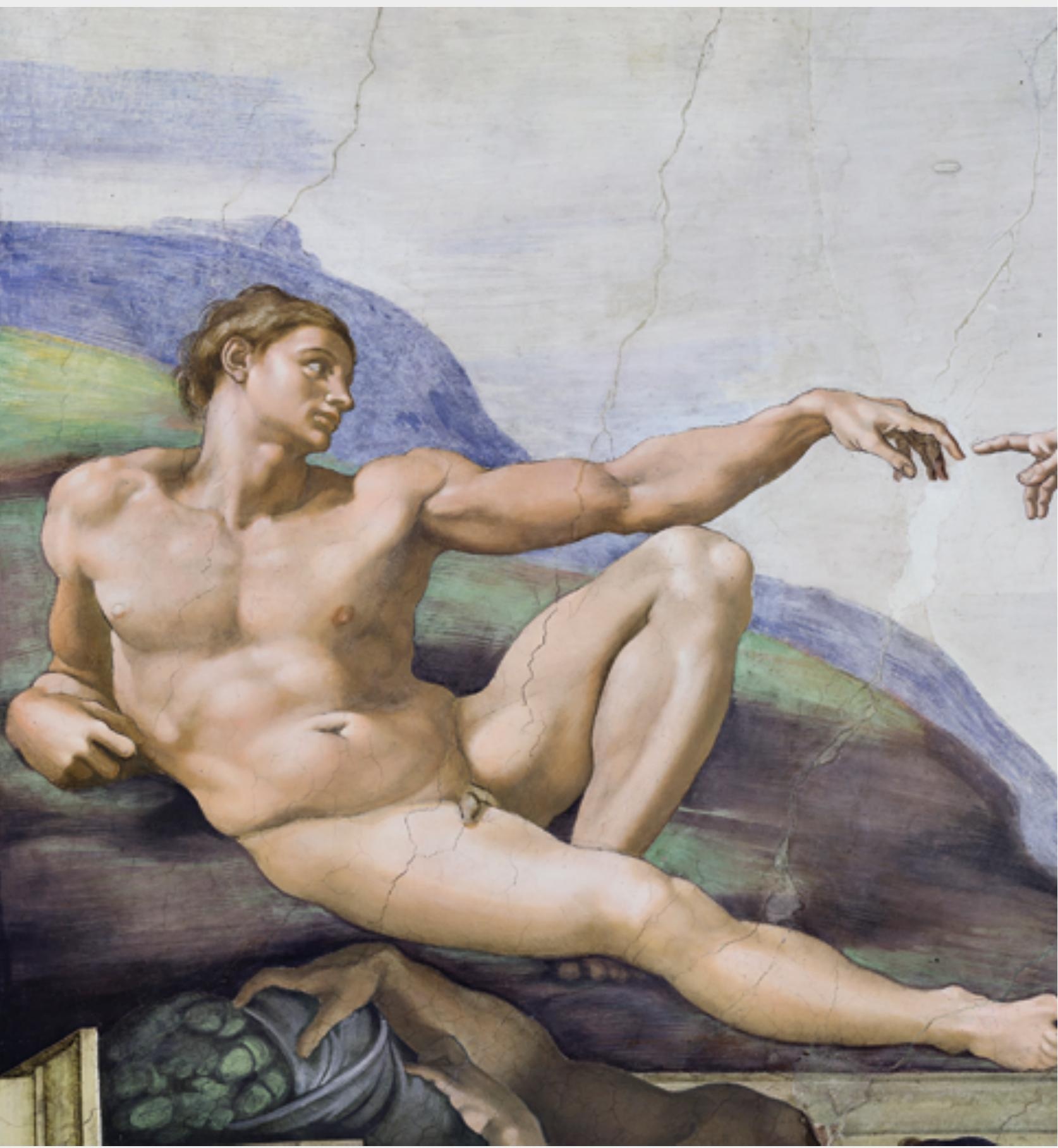

Creazione di Adamo (detalle). Miguel Ángel Buonarroti.

Capilla Sixtina. Por Concesión del Museo Vaticano, 2019. 


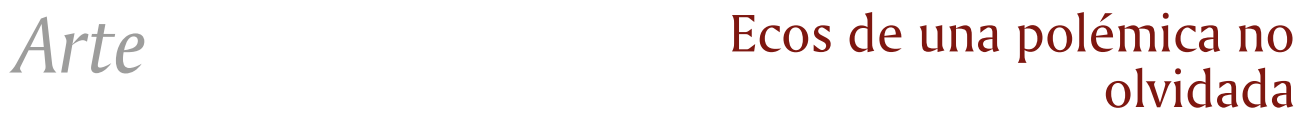

Alfonso Castrillón Vizcarra

Instituto de Investigaciones Museológicas y Artísticas

Universidad Ricardo Palma ccastrillon@urp.edu.pe

Lima-Perú

\begin{abstract}
Resumen
La limpieza de la bóveda Sixtina a partir de los años 80 creó entre los estudiosos del arte y los restauradores una polémica que no termina todavía. Arthur C. Danto en cuyo libro ¿Qué es el arte?, pone en tela de juicio la restauración conducida por Gianluigi Colalucci, cree que el hecho de haber limpiado la bóveda de sustancias extrañas le ha quitado la nobleza a la obra de Miguel Ángel, confundiendo la pátina con la suciedad acumulada a través de los años. Castrillón piensa que con toda razón se puede argumentar que al quitar la suciedad y devolverle los colores originales a la obra del pintor florentino, se ha procedido a buscar la verdad que es también una necesidad ética del público observador. El artículo va acompañado de una entrevista que el autor realizó el 2 de octubre del 2019 en Roma al Profesor Colalucci.
\end{abstract}

Palabras clave: Capilla Sixtina, Miguel Ángel, restauración, Gianluigi Colalucci

\begin{abstract}
The cleaning of the Sistine vault from the 80s created a controversy between art scholars and restaurateurs that has not yet ended. Arthur $C$. Danto in whose book "What art is?" the restoration of the equipment led by Gianluigi Colalucci is questioned. Danto, believes that the fact of having cleaned the vault of strange substances has taken away the nobility of Michelangelo's work, confusing the patina with the dirt accumulated over the years. Castrillón thinks that one can rightly argue that by removing the dirt and returning the original colors of the Florentine painter's work, one has proceeded to seek the truth that is also an ethical necessity of the observing public. The article is accompanied by an interview that the author carried out on October 2, 2019 in Rome to Professor Colalucci.
\end{abstract}

Keywords: Sistine Chapel, Michelangelo, restoration, Gianluigi Colalucci

En un corto viaje de estudio y de reencuentro con los amigos, llegué a Roma en 1987 y de entrada tuve una grata noticia: el profesor Enzo Borsellino, al teléfono, me preguntaba si quería subir al puente y ver de cerca los trabajos de restauración de la bóveda Sixtina. Accedí a su invitación sin duda, ya que desde mi época de estudiante no había vuelto al famoso recinto y, además, era un motivo para recordar las clases del Profesor Luigi Grassi, dictadas en 1964, con motivo del aniversario de la muerte de Miguel Ángel Buonarroti.

Entramos a la Capilla que ya lucía la mitad restaurada y de primera impresión me pareció estar en el set de filmación de "La Agonía y el Éxtasis", la famosa película protagonizada por Charlton Heston y Rex Harrison, tal era el vivo color descubierto por la restauración. Los trabajos hicieron necesaria la construcción de un puente apoyado sobre una ménsula 
corrida ${ }^{1}$ por lo alto conforme iban avanzando los trabajos en dirección al altar. Llegamos al puente gracias a un montacargas. En esos días se estaba limpiando La tentación de Eva y La expulsión del paraíso. Estábamos a un metro del techo pintado por Miguel Ángel y podía ver los cuerpos voluminosos de Adán y Eva en el momento de la tentación. Luego de saludar a Gianluigi Colalucci, jefe del proyecto, nos explicó el procedimiento del registro de cada figura, por el cual se podía saber en cuántas jornadas se había pintado, por ejemplo, Zacarías, que divisábamos desde el puente hacia la puerta de entrada. Las lunetas de los costados se habían pintado en tres días, pero la limpieza de la bóveda era complicada porque desde que la terminó Miguel Ángel en 1512, se le había aplicado cola aguada para afirmar los colores que, con el tiempo, el hollín y polvo terminaron oscureciéndola. Me parecía mentira estar tan de cerca del techo y hasta ver el resto de soguilla atada a un clavo de la época, dejado ahí por olvido. Recuerdo que Colalucci nos trató amablemente y nos regaló fotografías sobre el proceso de limpieza donde se podía ver el antes y el después, convincentes muestras a favor de la limpieza total de la bóveda.
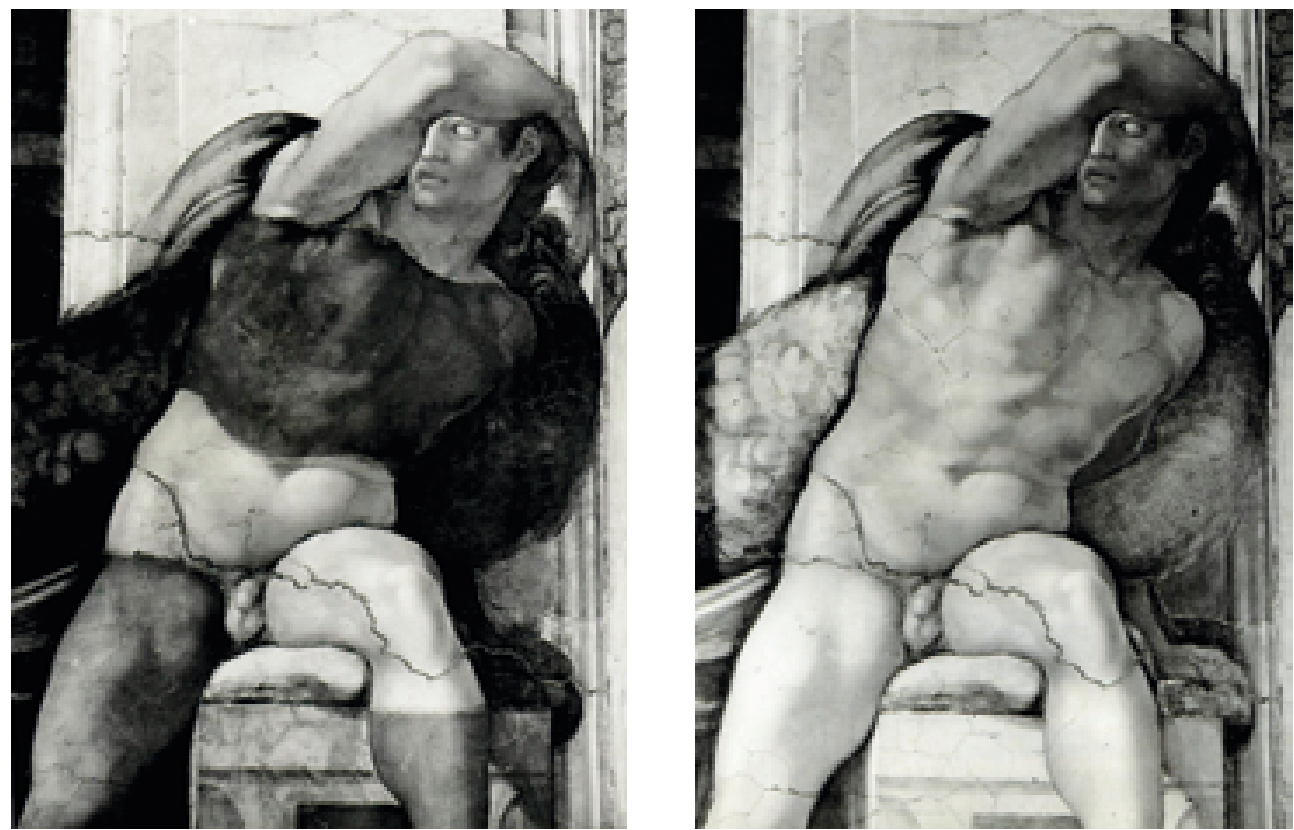

Fig. 1. Se puede apreciar en las imágenes el trabajo antes y después de la restauración. Las fotos en blanco y negro fueron tomadas por la NTV-Tokio para el Museo Vaticano en 1987.

Después de esa reveladora visita de 1986, no volví a interesarme en la polémica sino de la obra general de Miguel Ángel en mis clases de pre-grado, hasta que cayó en mis manos el libro de Arthur C. Danto, ¿Qué es el arte? (2013), donde en el capítulo 2, "Restauración y significado”, se declara contrario a la restauración. Adquirí otros libros sobre el tema, revisé los artículos que nos obsequió Colalucci y reforcé sus argumentos con otra visita posterior a la Capilla Sixtina que me hicieron meditar sobre el resultado. Fruto de esas reflexiones son las líneas que siguen, no desde el punto de vista filosófico, como propone Danto, sino del que la Historia del Arte nos puede dar a partir de la obra misma, la manipulación del

1 Ménsula, elemento arquitectónico que sobresale de un plano vertical y sirve para sostener alguna cosa. También se utiliza el término mensolone. El puente se apoyaba sobre ruedas fijadas a ménsulas de acero, vigas metidas en los huecos usadas por el mismo Miguel Ángel en el puente que usó en 1508. Dato proporcionado por el profesor Colalucci. 
restauro y las fuentes escritas. Ya sabemos de entrada que un enfoque filosófico es lo más subjetivo que existe en este campo.

El primer problema que salta a la vista, desde el principio, es la evidencia de un prejuicio, el epígrafe que da inicio al capítulo 2, donde Danto cita dos opiniones, una de Picasso que dice que "la Capilla Sixtina parece un enorme dibujo de Daumier" y otra de Jean Cocteau, en el que afirma que Miguel Ángel es "Un gran dibujante y un mal pintor". El primero es un juicio estético, donde Picasso se interesa por la oscuridad de la pintura a causa de la capa de suciedad y lacas que velaban los colores originales y que la hacían parecer a Daumier y el segundo, de tipo técnico, que descalifica a Miguel Ángel como pintor. En los dos casos sus juicios se basan en lo que ven estos artistas en 1930, es decir la pintura ennegrecida, y no la que en realidad estaba debajo. Sus juicios relativos, porque se basan en algo que en realidad no estaban viendo, permiten entrar en el terreno de la subjetividad donde Danto cree ver en el oscurecimiento "un ejercicio de transfiguración metafísica" (Danto, 2013, p. 65).

Dice Danto: "Ahora bien, si lo que parecía un ejercicio de transfiguración metafísica no era más que hollín de velas y humo de incienso, la obra puede haber perdido ahora una sublimidad incorrectamente atribuida durante mucho tiempo" (p. 67) ¿Qué le hace pensar a Danto que lo hallado después es menos sublime? A la leyenda de la bóveda se suma la del color oculto por muchos años. Si antes la Capilla parecía un "enorme dibujo de Daumier" (según Picasso), pienso yo, que ahora se parece a una obra del mismo Miguel Ángel, por ejemplo el Tondo Doni (1505-6). Picasso emite un juicio como hombre del siglo XX, con los referentes que tiene a la mano y el que más se parece al color oscurecido de Miguel Ángel es Daumier, pero al hacerlo revela que no conocía la pintura florentina del 500. Sin embargo, una mirada al Tondo Doni o a los cuatrocientistas en las paredes de la misma Sixtina, le hubiese hecho comprender el estilo "jardín florido" que se estaba imponiendo en la época, es decir colorido brillante, contrastante y cangiante. ${ }^{2}$ Lo cierto es que, luego de la limpieza de la bóveda, podemos afirmar que Miguel Angel era un gran conocedor de la física del color.

\section{Oscura inferencia}

La imagen de Jonás, ubicada casi en la orilla de Juicio Final, se ha hecho famosa por el despliegue de un dibujo en perspectiva que da la impresión de hundir hacia atrás el torso, mientras saca las piernas hacia adelante. Esta imagen que entusiasmó a los contemporáneos y sigue dejando perplejos a los visitantes actuales, para Danto está luchando por salir de la oscuridad, de una oscuridad invisible, porque no creo que se refiera al oscurecimiento debido al hollín y el polvo de los siglos, porque Miguel Ángel nunca pensó que con el tiempo se oscurecería la bóveda. Dice Danto: “¿Podría estar (Jonás) luchando por liberarse de la bóveda, por librarse de la fisicidad de la bóveda, como los esclavos luchaban unidos por librarse de la piedra, para llegar, en efecto, a cobrar vida?"

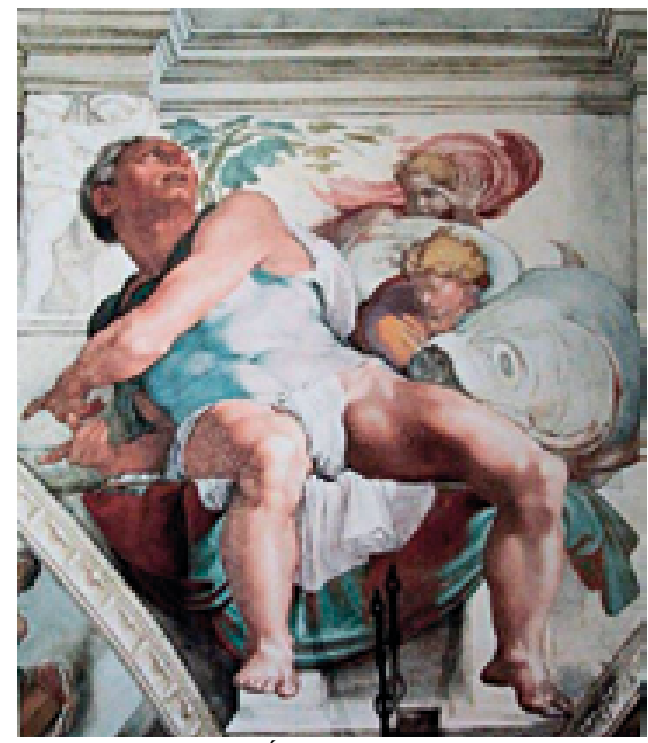

Fig. 2. Giona. Miguel Ángel Buonarroti. Capilla Sixtina. Museo Vaticano. Tomado de Giulio Busi, 2017.

2 Tornasolado: Una superficie cuando cambia de color dependiendo del movimiento, por ejemplo una cinta cuando la mueves, si es tornasolada cambia de color. 
(Ibídem, p. 73). ${ }^{3}$ Oscura inferencia, muy subjetiva, que no explica la postura de la imagen de Jonás, porque si éste hubiese sido pintado saliendo vomitado del vientre del pez estaría horizontal, en actitud de nadar; pero esta opción no le hubiese dado la oportunidad de lucir su destreza prospéctica. Al pintarlo sentado quizás se separa un poco de la historia bíblica, pero nos da una lección de dibujo en perspectiva que denota sus dotes y si además consideramos que Miguel Ángel no podía separarse del techo para ver cómo estaban quedando sus pinturas, los dibujos en escorzo resultan extraordinarios. Miguel Ángel se sale del libreto, de la tradición que daba más importancia al dictado del canon bíblico, es decir Jonás saliendo de las entrañas del monstruo, para sentarlo en un podio marmóreo luciendo una extravagante postura. ¿No les parece un exabrupto pre-manierista?

\section{Obsesiva pregunta}

Si hay una duda constante en Danto es saber a ciencia cierta si la capa de suciedad y cola que se ha quitado de la bóveda no se ha llevado consigo trazos de pintura al seco, porque "debemos decidir si lo que se ha quitado es suciedad o significado" (Ibídem, p. 68). Según la tradición italiana de la época, la pintura al seco se aplicaba como retoques para dar algunas sombras, pero no para concebir las figuras enteras, ni rellenar cuerpos y vestidos (Colalucci, 1986, p. 260). ${ }^{4}$ Si se quita la suciedad puesta por el tiempo, no por Miguel Ángel, desaparece un significante que el pintor no quiso darle: una pintura castigada por las borrascas tridentinas, en cambio el pleno color aparece como un canto postrero a la sensualidad y la alegría de vivir.

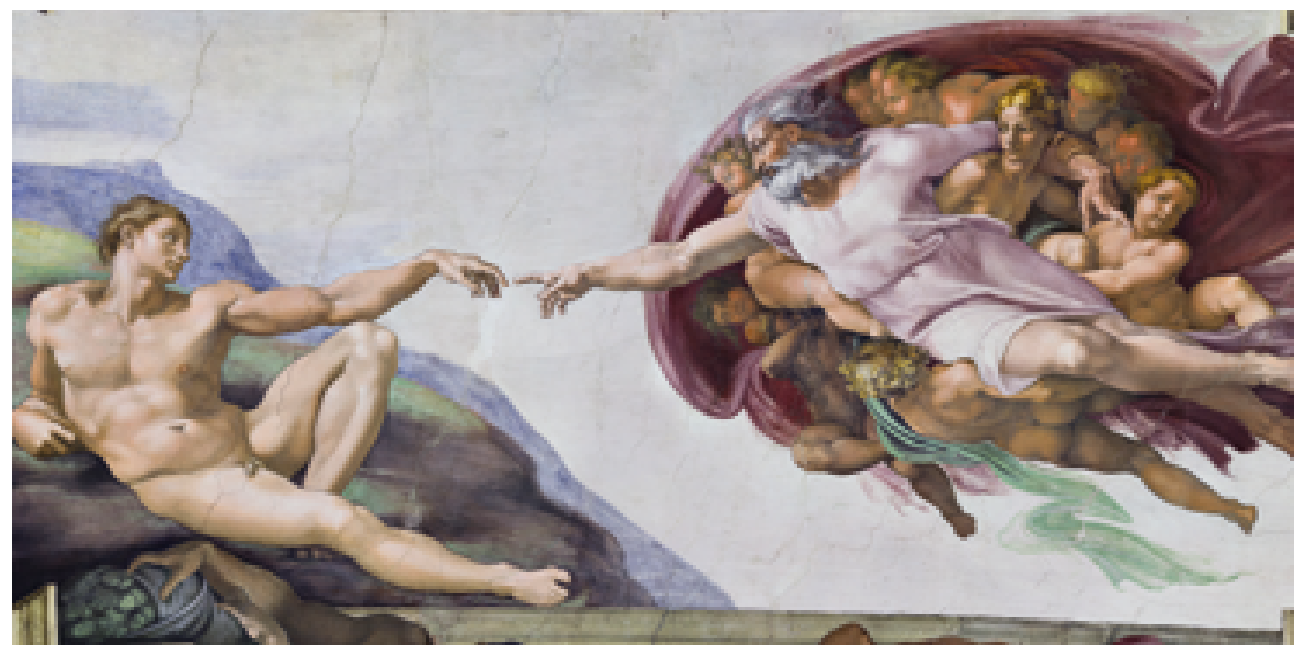

Fig.3. Creación de Adán. Miguel Ángel Buonarroti. Capilla Sixtina.

Por Concesión del Museo Vaticano, 2019.

A estas alturas podemos decir que Danto no es muy feliz con los ejemplos que escoge: para argumentar que la bóveda no debe intervenirse, en lo posible, para devolverle sus valores originales, se vale de las esculturas de los esclavos de la Academia, dejadas, como se sabe, sin terminar. "Pero supongamos que (...) alguien decide tallar toda la piedra que queda sin tallar, para liberar la figura tal como pretendía Miguel Ángel” (Danto, Op.

3 Danto se refiere a los esclavos para la tumba de Julio II que quedaron sin terminar.

4 Según Gianluigi Colalucci, Miguel Ángel usó el recurso de la pintura al seco "peraltro in misura minima sulla volta e mai nelle lunette" (No obstante en mínima medida sobre la bóveda y nunca en las lunetas) Colalucci en la entrevista que le hicimos, declaró que el agua y las esponjas usadas cada día en la limpieza del fresco, se examinaban minuciosamente con el fin de ver si habían restos de pintura. 
Cit.p.68), ¿Sería correcto? Hoy, gracias a innumerables estudios, sabemos que Miguel Ángel las dejó inacabadas por falta de tiempo o porque quiso significar que los esclavos luchaban con la piedra para salir en libertad. La teoría del non finito ha sido reconocida por muchos investigadores y hoy día a nadie se le ocurriría quitar las partes que el artista ha dejado inconclusas para mostrar las esculturas como en realidad las había imaginado Miguel Ángel, es decir "terminadas". Las dos hipótesis arriba mencionadas pueden ser ciertas; tantos eran los encargos que recibía el artista que bien ha podido saltar de una comisión a otra para contentar a sus clientes y con el tiempo constatar que, en el caso de los esclavos, dejar el mármol sin tallar coincidía con la idea de la lucha por salir de la materia bruta. ${ }^{5}$ Esta hipótesis deja sin efecto la idea peregrina de Danto de una amputación del material sin esculpir por ser improbable. En cambio la mugre que ocultaba el verdadero color de la Sixtina no fue responsabilidad del artista, ya que él no sabía, como hemos dicho, que con el tiempo se ennegrecería.

\section{Miguel Ángel un pintor notable}

Miguel Ángel comenzó los trabajos en la Sixtina en 1508 y los terminó en 1512, es decir, su intervención duró veinte meses. Al principio, dado lo arduo del trabajo previsto, contrató ayudantes que llegaron de Florencia, pero que lo sirvieron por poco tiempo, pues viendo que estaban muy lejos de sus expectativas, los despidió a todos y se quedó solo "senza aiuto pure di chi macinassi i colori" (Vasari, 1967, p.140). ${ }^{6}$

Se sabe por Condivi (1964, p. 125) y Vasari (Op. Cit., p.137) que cuando el Papa Julio II le propuso a Miguel Ángel pintar la Sixtina, el artista se negó, alegando que él era ante todo escultor. Desde luego que el escultor prefería terminar el encargo de la tumba de Julio II que trabajar en una técnica que conocía poco. Estaba de por medio, también, el amor propio frente al joven Rafael, que apadrinado por Bramante presionaba al Papa para emplearlo en las decoraciones del Vaticano. Miguel Ángel deseaba retocar algunas imágenes al seco pero lo cierto fue que, por la prisa que demostraba el Papa en inaugurar la capilla, no pudo dar "la última mano" (Ibídem, p. 139) a la bóveda, como era costumbre, es decir, no la terminó.

El temor de Danto de que la limpieza se llevara consigo los retoques hechos por Miguel Angel persiste en las páginas de su artículo. Sin embargo la restauración última no deja dudas sobre la presencia de pintura al seco, inexistente en las lunetas, pero muy poca de la mano del artista en la bóveda, según Colalucci, quien además da cuenta minuciosa de la utilización de colas de diverso tipo a lo largo de los años. El ennegrecimiento general del techo se debe pues a las diversas capas de esas sustancias que la tradición permitía pensando que aclararía la superficie, consiguiendo en cambio, con el tiempo, ese velo oscuro que caracterizó la bóveda hasta 1980.

Después de la restauración, llamó la atención del público el color brillante y luminoso que ofrecía la bóveda, haciéndonos recordar el set del film "La agonía y el éxtasis", como he mencionado líneas arriba, y aunque parezca irrespetuosa respecto al original, esa era la sensación que causaba a primera visita: un deslumbramiento total. Pero es por demás curioso el hecho de que ni Condivi ni Vasari, sus contemporáneos, hayan manifestado su entusiasmo por el colorido miguelangelesco, enfocándolo sobre todo en la pericia del dibujo y los atrevidos escorzos, considerados la suprema práctica del arte de la pintura. No el color, sino el dibujo. Y parece que la explicación la tenemos en que esa era la estética del momento. Es el único tema en que Danto está de acuerdo con la restauración:

\footnotetext{
5 "No tiene el gran artista ni un concepto/ que un mármol sólo en sí no circunscriba en su exceso/ ma solo a tal arriba/ la mano que obedece al intelecto”. Miguel Ángel, Soneto 151.

6 "sin ayuda de quien le preparara los colores"
} 
El esquema del color, del cómo está ahora, es bastante consistente con lo que uno ve en otros lugares del Vaticano, en las estancias y los pasillos (...). Opino que sólo por estas razones los colores eran invisibles para los contemporáneos de Miguel Ángel (Danto, 2013, p.76).

Por otro lado, hay que tener en cuenta que los problemas de conservación de la bóveda comenzaron relativamente temprano, según Colalucci (1986, p. 262), “en torno a 1547 Govio escribía que (la obra de Miguel Ángel) se va deteriorando por la sal nitro (nitrato de potasio) y las rajaduras". Es más, la bóveda se pudo gozar en el esplendor de su colorido muy pocos años porque ya en la época de la primera edición de Las Vidas de Vasari (1568) "la bóveda era con toda seguridad irremediablemente oscurecida por el polvo, del hollín y las primeras aplicaciones de cola" (Mancinelli, 1986, p. 64).

A pesar de las críticas, pienso que el éxito de la limpieza se ha debido al plan y la intención del proyecto liderado por Colalucci, que ha tenido en cuenta la ciencia histórica del arte y la técnica, como cuerdas separadas, una es el significado (sujeto de interpretación) y otra la ciencia que aborda la obra como significante (fisicidad) de tal manera que ha tratado la bóveda "como mero objeto físico", aunque esta afirmación levante las iras de sus detractores. Danto dice "Una obra de arte no es sino un significado encarnado, y su significado es tan intrínsecamente relacionado con el objeto material como el alma lo está con el cuerpo" (Danto, 2013, p. 76). Pero el alma, ¿dónde está el alma? Cuando se habla de ciencia no importa dónde está el alma y el cirujano hace su trabajo profesionalmente, como el restaurador. Colalucci expone sus intenciones: "Creo que la mejor manera de trabajar en Miguel Angel es la pasividad absoluta (...) Si tratamos de interpretar una obra de arte, dicha interpretación acaba imponiendo sus condiciones durante el proceso de limpieza" (Ibídem, p. 70). Es justamente lo que hace Danto cuando trata de imponer su lectura neo platónica a lo que era, desdichadamente, el recubrimiento de polvo y hollín de la bóveda antes de la limpieza. Así como Danto dice que al quitarle las sombras de hollín y polvo se ha privado a la bóveda de su significación "filosófica”, podemos con toda razón argumentar que al quitar esas sombras y devolverle los colores originales, se ha procedido a buscar la "verdad”, que es también una necesidad ética del público observador.

\section{Entrevista al profesor Gianluigi Colalucci. Roma, 2 de octubre de 2019}

Alfonso Castrillón (AC): ¿Qué cosa le indujo a aceptar el encargo de la limpieza de los frescos de Miguel Ángel en la Capilla Sixtina, trabajo de tanta responsabilidad, lo tomó como un desafío profesional?

Gianluigi Colalucci (GC): No, en realidad no fui llamado para hacer el trabajo, yo era jefe restaurador y tenía la responsabilidad del mantenimiento de todos los frescos, todas las pinturas del Museo Vaticano y también fuera de él. Era una praxis normal de controlar las condiciones de las pinturas en general y cada año se hacía la spolveratura ${ }^{7}$ del Juicio Final; ésta era una tradición antigua y cuando entré al Vaticano me ofrecí para hacer la limpieza en las tardes, cuando no había gente, condición extraordinaria para ver de cerca el fresco que era misterioso e incomprensible.

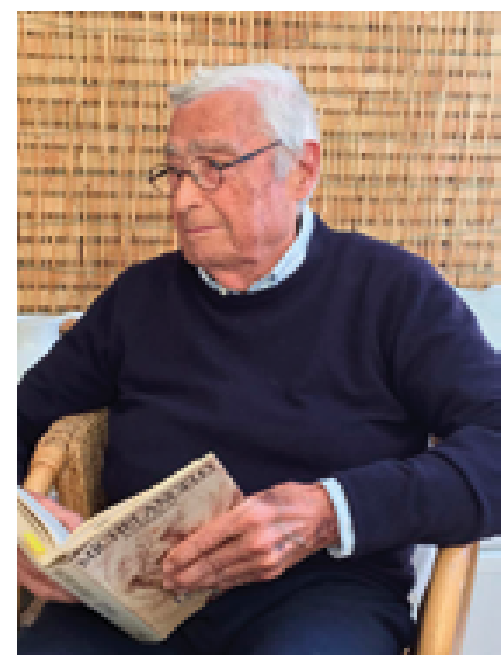

Fig.4. Profesor Gianluigi Colalucci. Fotografía cortesía de Enzo Borsellino, 2019.

7 Retirar el polvo 
Después hemos comprendido por qué, con el pasar del tiempo se habían formado sobre el fresco depósitos de sustancias que dejaban ver la pintura, pero no los colores, como si en un automóvil se cubrieran de fango las lunas. Sin embargo esta intervención se había previsto solo para el Juicio final y no para la bóveda que era tan alta. Nosotros, en un cierto punto hemos comenzado la restauración de los frescos del tardo $500,{ }^{8}$ aquellos que están a la entrada de la Capilla Sixtina que se dañaron por la caída de sus muros. ${ }^{9}$ Estábamos cerca de la bóveda y entonces yo pedí que se levantara el puente hasta llegar a una luneta que representaba a Eleazar. Vi y comprendí que había material extraño sobre la bóveda y como tenía un pañuelo de papel en el bolsillo, lo mojé con saliva e hice un tassello ${ }^{10}$ de limpieza de dos centímetros, más o menos del tamaño de una estampilla y en el instante comenzó a aparecer un color extraordinario. Entonces advertimos a Mancinelli historiador de arte y jefe de los Trabajos y también a Pietrangeli que era el director general le preguntamos ¿qué hacemos?, porque habíamos descubierto algo importante que no se podía desconocer. El director dijo que debía seguir un poco más porque el tassello era demasiado pequeño. Necesitábamos una tira que pasara por varios colores y cuando la vieron Pietrangeli y Macinelli dijeron que había que tomar una decisión, porque lo que habíamos encontrado no podía ignorarse. Debo decir que estábamos en 1980 y la restauración en esos años había desarrollado técnicas mucho más modernas respecto a las de 1940 . El director de aquella época, Viaggetti, era un pintor que tenía a su cargo la conservación de las pinturas del museo; él ya había escrito que los frescos de la bóveda de la Sixtina se veían medio ahumados; sin embargo en aquel entonces era muy pronto para dar esa noticia a la opinión pública y a los historiadores del arte de aquella época, porque existían muchas críticas sobre el tema de la conservación, pero en 1980 ya no se podía ignorar completamente que contábamos con todos los medios para hacer los trabajos necesarios y con seguridad. Así Pietrangeli, que era el director en esa época, pidió unos días para pensar y después dijo: "limpiemos esta luneta, la presentamos a todos y abramos una discusión; si no va bien se termina aquí, si va bien seguimos adelante”. Estábamos todos entusiastas y por lo tanto nos dieron un buen empuje para continuar, entonces fui el encargado de preparar el proyecto con los tiempos, como las fechas, tanto de la bóveda como del Juicio. El cálculo resultó de unos doce años, que me preocupaba, pero lo hemos casi mantenido porque en realidad ha durado catorce años, ya que un año lo empleamos en estudiar el Juicio Final, porque era considerado una cosa aparte y después hemos descubierto por qué. En el pasado habían tratado de limpiarlo en diversos momentos, pero lo ensuciaban aún más; había una gran confusión. Para un restaurador es difícil entender esta materia, pero después de haber estudiado hemos empleado una técnica de limpieza distinta, porque en el cielo del Juicio se emplea lapislázuli que es un pigmento delicadísimo, mientras que este color no existía en la bóveda. Por lo tanto no se podía usar el mismo tipo de disolvente para intervenir el Juicio. Hemos hecho esta modificación y basta. Una cosa es cierta, me parecía bastante interesante y me decía a mí mismo que el trabajo se podía hacer; es un fresco bastante bien conservado, no debemos tener miedo, tenemos un laboratorio de investigación científica que nos asiste en todo momento y así con esa seguridad hemos seguido adelante. Después intervienen los japoneses que hicieron algo excepcional: un documental del trabajo de la limpieza. Por lo tanto está todo documentado: el gabinete de investigación científica, etc. Hemos usado el agua destilada (desionizada) para limpiar; la usada la poníamos en un recipiente que iba todos los días a un laboratorio de investigación científica para analizar si habían restos de pigmentos en el agua.

8 Se refiere al renacimiento tardío del "quinientos" o siglo XVI.

9 Las pinturas de los muros fueron restauradas entre 1573 y 1574 por de Matteo de Alessio (Disputa del cuerpo de Moisés) y en 1572-85 por Hendrick van der Broeck (Resurrección de Cristo).

10 Cala de limpieza 
(AC): ¿Después de qué pruebas preliminares se comenzó la restauración; desearía saber en qué momento se sintió seguro de iniciar el trabajo?

(GC): Hemos comenzado con la limpieza de dos figuras de la luneta de Eleazar, porque el solvente podía ser graduado. Entonces nos dimos cuenta que la pintura de Miguel Ángel estaba bien conservada y sobre todo límpida y que dejar aquello que llamaban "la pátina", en este caso resultaba un problema. No es el caso del fresco, pues lo que se tenía era suciedad y humo de carbón, porque en esa época encendían braseros y además se le colocaban sustancias puestas por los conservadores, que se utilizaban hace un siglo para reavivar los colores, como hiel de buey, cola animal, goma arábica, que con el tiempo se oscurecen; algunas de estas sustancias mezcladas con el humo del carbón se vuelven de color pardo, por lo que hemos hecho una graduación hacia el nivel justo, que según nosotros llegaba a la superficie del fresco. Después de 50 años, con un ligero velo sin tocar el color vivo y con la elección del nivel de limpieza como una parte integrante de la restauración de una pintura, (porque ya que en ese momento se puede definir cualquier cosa), entonces es la cultura la que te debe ayudar a estar en la parte justa y la cultura cambia, por lo que, una restauración como ésta, hecha en 1950 no hubiese sido aceptada. Como en 1980 ya estábamos más adelantados, porque recuerdo la atención que Brandi ponía en la conservación de la pintura. Yo estaba en el Istituto de Restauro cuando Brandi fue director, y siempre había ese temor, pero me di cuenta que si esta pintura tan delicada (que parece una pintura fuerte), en realidad lo que es fuerte es el fresco, pero la pintura deja ver una evidente delicadeza en el tratamiento de la musculatura y en otras partes de manera extraordinaria. Si se dejaban zonas manchadas de suciedad, le hacían un gran daño porque el sombreado de la musculatura se confundía con las manchas por ligeras que fuesen. Por lo tanto me pareció lógico (y también al equipo de restauradores) llegar a un nivel que dejara una parte muy antigua de la capa de suciedad y se borrara todo el resto. La cuestión controversial fue siempre la del sombreado de los cuerpos, pero se puso especial cuidado en conservarlos.

(AC): ¿En sus escritos usted dice que Miguel Ángel utilizó “pocas veces la pintura al seco”, pero no dice cuántas, cinco, diez o veinte?

(GC): Las veces que Miguel Ángel ha pintado al seco en la bóveda, han sido documentadas; no hemos contado cuántas, pero sabemos que esta tradición proviene de Giotto y más tarde Cennino Cennini. Yo he trabajado en la Capella degli Scrovegni, donde Giotto utilizó pintura al seco para el color azul, como los utilizados en el Juicio Final. Depende mucho de los colores que se usen, porque si se emplean colores inconvenientes en cierta manera se genera un problema para el restaurador, pero él lo sabe y entonces va adelante con mucho cuidado. Lo mismo vale para Miguel Ángel, nosotros hemos partido convencidos de que había mucha pintura al seco (por la proporción del cielo del Juicio), porque en esa situación un poco confusa, era difícil saber cómo andaban las cosas, por lo cual todas las partes que habíamos considerado pintadas al seco, después vimos que eran partes muy pequeñas como la corrección de un hombro o de un ojo, las hemos ubicado porque si hubiésemos ido a limpiar indiscriminadamente hubiésemos perdido todo y son partes al seco que tienen una cierta importancia; sin embargo otras partes son un seco que deriva de la giornata del día sucesivo, ${ }^{11}$ porque poniendo una giornata al lado de la otra se forma una sutura; si el pintor no la quiere hacer ver pinta al seco la parte de la sutura y este seco se vuelve lentamente fresco porque uno de los intonacos ${ }^{12}$ son húmedos, por lo tanto son casos muy particulares. No le puedo decir el número de veces que hemos encontrado pintura al seco en la bóveda; para eso hay que ver todos los gráficos que figuran en el libro que ha

11 Las giornatas o jornadas son las medidas utilizadas por los restauradores, por ejemplo se ha comprobado que el trabajo hecho en las lunetas de la Capilla ha durado tres jornadas para acabarla.

12 Revoques, revestimiento. 
editado el Vaticano sobre la restauración de Capilla Sixtina. Luego viene el problema de los retoques de los restauradores del pasado, antes de limpiar cada pintura al seco, tanto las originales como las restauradas, las hemos impermeabilizado con la resina paraloid ${ }^{13}$, entonces cuando se hace la limpieza si se usa agua, porque estos solventes son a base de agua, todo lo que debe de desaparecer desaparece, lo que se ha impermeabilizado queda, porque el agua no le hace mella. Nosotros hemos tomado esta precaución, es decir usar los retoques de los restauradores y fijar con paraloid, después de lo cual, punto por punto se iba limpiando ligeramente cuidando de no tocar la impermeabilización y después poco a poco se llegaba al punto que era claramente un retoque y esto se ve analizando los colores (luego explico por qué) o en cambio era una parte original que debía quedar.

(AC): ¿Es verdad que cada día, después de la limpieza, examinaban los algodones para controlar si había restos de pintura al seco?

(GC): No solo de pintura al seco, sino también de pintura al fresco, porque el solvente podía tocar el fresco, por eso mandábamos las cubas de agua a examinar a los laboratorios. No hemos usado algodón porque araña el fresco, sino más bien esponjas naturales, pequeñas, esterilizadas, por lo tanto al analizar el agua y las esponjas, hubiésemos descubierto si había pigmento para tomar las debidas precauciones.

(AC) Algunos estudiosos han declarado que hubiese sido indispensable, considerar la intervención sobre los frescos con el auxilio de la filosofía, porque quitar la suciedad aportada por los siglos, representaba eliminar el significado logrado por la obra del tiempo ¿Cuál es su opinión?

(GC): Mi opinión es (también la de todo el equipo del Museo del Vaticano), de estar en línea con el pensamiento de Cesare Brandi. Su pensamiento puede resumirse en dos grandes líneas: la instancia histórica y la instancia estética. Como la instancia histórica es todo lo que se ha acumulado con el tiempo, la instancia estética es la obra en sí. Según Brandi, la instancia estética vence a la histórica, porque es más importante recuperar la pintura original que una cosa sobrepuesta adjunta, la suciedad, o como creían los filósofos del 700 y 800 , que el humo nobilizaba la pintura, etc. Lo he dicho antes, la restauración sigue la cultura del tiempo. Nosotros en los 80 estábamos en condiciones de aceptar la pintura de Miguel Ángel tal como era y aquello que podía ser la instancia histórica, es y no es, toda la suciedad que se había acumulado en el tiempo. Dejemos la polémica reciente, pero en grandes líneas no debemos ser arbitrarios, lo pienso yo como lo piensan otros. Es necesaria una filosofía, hacerse de un pensamiento fuerte. Por lo menos en Italia, todavía no obstante exista una discusión entre los críticos, la filosofía de Brandi es la que da las bases para razonar sobre los frescos, sobre la limpieza y la intervención. Es necesario tener un pensamiento porque no se puede obrar sin él.

(AC): Leo en su trabajo que usted piensa que la restauración y la historia de arte son cosas paralelas, pero que para el restaurador el objeto artístico debe ser considerado principalmente en su fisicidad, porque actualmente la objetividad es la base para proceder de modo adecuado ¿Qué otra cosa puede agregar?

(GC): Puedo aclarar el concepto, es decir el restaurador trabaja sobre la materia, no trabaja sobre la concepción de la obra; trabajar sobre la materia significa poner gran atención y conocimiento de la materia que forma parte de la obra; cuando uno procede de esta manera, difícilmente se produce daño. Este razonamiento evita contar con los abusos del

13 Paraloid es el nombre comercial de un producto. Es una resina termoplástica. Químicamente se la conoce como un copolímero de etyl-metacrilato. Puede ser utilizada como revestimiento, como adhesivo, consolidante y otras aplicaciones dependiendo del grado de disolución (Datos proporcionados por la arquitecta Rosanna Kuon Arce, a quien agradecemos su colaboración) 
pasado, cuando el restaurador interpretaba la obra y la corregía a su criterio (o le agregaba cosas que no convenían al fresco). Para evitar todo esto es necesario que el trabajo sea lo más objetivo posible.

(AC): Profesor Colalucci, su trabajo ha recuperado el color original de Miguel Ángel. ¿Por qué Condivi y Vassari no le dieron importancia en sus escritos a la diversidad colorística de Miguel Ángel, cuál es su opinión?

(GC): Pienso que cuando Miguel Ángel pintó los frescos, los colores eran los mismos que vemos ahora, por eso los manieristas, que parecían no tuvieran padre, con todos esos colores que utilizaron, en realidad se ha visto que él era el padre, pero en el momento que Miguel Ángel pintó, no fue considerado un escándalo. Debo decir además que su pintura hace un cierto efecto, porque son los colores que siempre ha utilizado la tradición en Florencia. No es que él use colores diferentes a los pintores del 400, sino que los extiende sobre superficies diferentes, es decir, si tomamos los frescos de ésta época que están debajo y miramos uno por uno los colores: rojo, amarillo, azul, etc. vemos que en el 400 son colores que dan vivacidad a la composición, pero no crean un fuerte impacto. ¿Por qué Miguel Ángel crea ese impacto fuerte? Porque sus figuras son grandísimas y si él pinta una tela verde resulta enorme porque es vista desde abajo. Es la grandeza física de la figura lo que crea algo nuevo.

(AC): ¿Esto quiere decir que Miguel Ángel sigue la tradición de los pintores del $400^{14}$ que están debajo?

(GC): Miguel Ángel sigue la técnica de los pintores tradicionales desde Cennino Cennini, Giotto, etc. Esta técnica del fresco es la que es, así de simple, no admite dudas, ni excepciones o es esa o no sale bien, por lo tanto Miguel Ángel interpreta el fresco de la manera más rigurosa porque pinta todo en esta técnica, al igual que esas sombras ligerísimas que son acuareladas; mientras que en el 400, se agregaban colores que el fresco no admitía y por lo tanto se usaba mucho la pintura al seco sin que esto significase un escándalo. Era lo normal, por lo tanto Miguel Ángel interpreta lo mejor posible la tradición de esta técnica, porque su trabajo ha quedado intacto.

(AC): El Cangiante realizado con un pincel casi seco, como dice Cennini, ha sido adoptado por Miguel Ángel. ¿Qué nos puede decir al respecto?

(GC): El Cangiante se hacía antes de Miguel Ángel, quien ha seguido y mejorado la técnica de pintores anteriores, porque a él le servía para "romper" el color y hacer los pasajes de color más naturales. El Cangiante ya se usaba en la tradición pictórica, como se observa en la pintura de Giusto de Menaboi ${ }^{15}$ que tuve la oportunidad de restaurar en Padua hace tiempo.

(AC): Bien profesor, le agradezco mucho porque esto en verdad es una voz viva que tiene tras de sí una proeza, un fantástico trabajo que ha salvado la pintura y esperamos dure para siempre.

(GC): Yo pienso que debería durar más, pero el futuro nadie lo sabe, aunque existe una razón por la cual podría conservarse muchísimo más tiempo, y es dándole una continua conservación preventiva, estando atentos a la contaminación, al anhídrido carbónico, etc. El Museo del Vaticano, a través de su laboratorio de restauración tiene el encargo de hacer cada año el control del estado de conservación en la Capilla; otro inconveniente es el polvo sutil que es difícil de eliminar a pesar de que se ha renovado el sistema antipolvo para la

14 Los pintores del 400 a los que nos referimos son Sandro Botticelli, Pietro Perugino, Biagio d'Antonio, Ghirlandaio, Cossimo Rosselli y Luca Signorelli.

15 Artista de la época del 300. 
limpieza del ambiente. Hay otro asunto también que nos preocupa, que es la cantidad de visitantes en la Capilla Sixtina, porque siempre persiste el problema del anhídrido carbónico producido por la respiración de los visitantes. No hay velas ni otras luminarias por lo que creo que durará muchos años más.

Los frescos de Miguel Ángel son de tal manera resistentes por que él ha usado un revoque que ningún otro usaba, es decir uno que solo se podía hacer en Roma, que es la puzolana ${ }^{16}$. Miguel Ángel descubrió que esta mezcla era muy fuerte porque funcionaba también bajo el agua, pero él tuvo a su vez un problema: que la puzolana resultó ávida de agua y cuando uno pasaba el pincel húmedo absorbía de inmediato esa humedad y el color no corría. Entonces Miguel Ángel, modifico las proporciones, agregó más cal al intonaco, llamado intonaco grasso, término que utilizan los albañiles, porque en lugar de ser la proporción 3 a 1 , es 3 a 2, donde la cal es mayor. De esta manera el intonaco hace posible que los pinceles corran fácilmente, pero existe un defecto que desde abajo no se nota, nosotros lo hemos visto de cerca y es que ese intonaco se cuartea, se agrieta, pero esas fisuras no son peligrosas porque la superficie es rica en calcio y la tensa un poco, por lo tanto Miguel Ángel ha trabajado para que la obra durase para siempre.

$(\mathrm{AC})$ : Alguien ha dicho que quitando la suciedad se perdía la nobleza de la obra de Miguel Ángel. Pienso que al contrario, desvelando su verdadero color, se trabaja en busca de la verdad, es decir se trata de un hecho ético, de descubrir el verdadero color del pintor florentino ¿Cuál es su opinión profesor Colalucci?

(GC): Debo decir que la obra de Miguel Ángel es muy noble aun cuando estaba cubierta por la suciedad. Vista de cerca, era de tal manera bella, pero no era "legible" por la capa de polvo que la cubría y esto no dejaba apreciar la estructura arquitectónica de la bóveda como la concibió él; ahora sin embargo se ve claramente, muy limpia y nítida. No puede pensarse que Miguel Ángel hiciera todo ese trabajo para después ensuciarla y envejecerla.

(AC): De nuevo profesor le agradezco mucho en nombre de nuestro Rector, por habernos recibido esta tarde y haber conversado sobre su trabajo en la Capilla Sixtina.

\section{Vocabulario de la entrevista a Colalucci}

Tomado de Dizionario della Crítica d'Arte de Grassi y Pepe, 1978.

Campiture: es el espacio o campo del fondo de una pintura.

Intónaco: Del latín tunicare, vestir. Revestimiento que se da al muro.

Arricciato: Muro arricciato, es la segunda capa de intónaco que se extiende sobre la pared.

Tassello: trozo pequeño de piedra o mármol con el que se compone un mosaico; por extensión pequeño rectángulo que sirve de prueba al comenzar la limpieza de una pintura o fresco.

Arriccio: espalmar sobre un muro la primera capa de calcina.

Paraloid: resina acrílica B72 en solución del 3\%.

Cangiante: graduación de un color hacia el más claro o hacia el más oscuro; también se traduce como tornasolado.

Pozzolana: Un tipo de intónaco que sólo se usa en Roma por la calidad de la arena. La proporción acostumbrada es 3 a 1 ( 3 de arena por una de cal)

Intónaco grasso: Un tipo de pozzolana cuya proporción es de 3 de arena por 2 de cal.

Atramento: Atramentum los colores.

16 Tierra especial que solo existe en la ciudad de Roma 


\section{Referencias bibliográficas}

Alberti, L. B. Sobre la pintura. Valencia: Fernando Torres Editor, 1976.

Ball, P. La invención del color. México: Fondo de Cultura Económica, 2003.

Barocchi. P. Trattati d'arte del Cinquecento: fra Manierismo e Controriforma. Serie:Scrittori d'Italia / Laterza. Roma: Bari : Laterza, 1960-1962.

Beck, J. y Daley, M. La restauración de obras de arte. Barcelona: Ediciones del Serbal, 1997.

Buonarroti, M. Á. Sonetos completos. Madrid: Editorial Cátedra, 1987.

Busi, G. Michelangelo, mito e solitudine del Rinascimento. Milano: Mondadori, 2017.

Cennini, C. El Libro del Arte. Madrid: Ediciones Akal, 2014.

Cennini, C. Il libro dell'Arte. Vicenza: Neri Pozza Editore, 1982.

Cittá del Vaticano. Roma: Edizione e foto di Bruno Del Priore, 1967.

Colalucci, G. Io e Michelangelo. Vaticani: Edizioni Musei Vaticani, 2016.

Colalucci, G. Tecniche di restauro. (Dispense, copias proporcionadas por el autor), 1986.

Condivi, A. "Vita di Michelangelo". En Michelangelo. Recupero, J. Roma: De Luca editore, 1964.
Conti, A. Michelangelo e la pittura a fresco: tecnica e conservazione della Volta Sistina. Firenze: La Casa Usher, 1986

Danto, A. C. Qué es el arte. Barcelona: Danto, Paidós Ibérica, 2013.

Doliner y Blech. Isegreti della Sixtina, il mesaggio segreto de Michealangelo. Milano: Rizzoli, 2008.

Francastel, G. El Quattrocento Florentino. Bilbao: Ediciones Garriga, S.A., 1958.

Grassi, L. Introduzione all'Arte di Michelangelo, Roma: Edizione dell'Ateneo, 1964.

Grassi, L. e Pepe, M. Dizionario della critica d' Arte, Torino: UTET, vol. 1 y 2, 1972.

Mancinelli, F. Michelangelo a nuovo. Atlante/Arte, Ottobre 1986.

Néret, G. Miguel Ángel. México:Taschen, Editorial Cordillera, 2011.

Recupero, J. Michelangelo. Roma: De Luca editore, 1964.

Vasari, G. "Le vite de' piu' eccellenti pittori, scultori e architettori". Vol.VII. Publicado por Arnoldi. Novara, Istituto Geografico de Agostini, G.Previtali, P.Ceschi e F.Negri, 1967.

Recibido el 7 de julio de 2019 Aprobado el 30 de octubre del 2019 


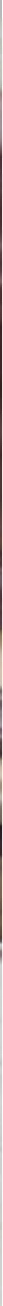

Creazione di Adamo (detalle). Miguel Ángel Buonarroti. Capilla Sixtina. Por Concesión del Museo Vaticano, 2019. 